\title{
A spatial econometric empirical research on the impact of industrial agglomeration on haze pollution in China
}

\author{
Hong Zhao ${ }^{1} \cdot$ Xiaoxi $\mathrm{Cao}^{2} \cdot \mathrm{Tao} \mathrm{Ma}^{2}$ (i) \\ Received: 2 June 2020 / Accepted: 20 July 2020 / Published online: 4 August 2020 \\ (C) The Author(s) 2020
}

\begin{abstract}
Based on statistical data on 30 provincial administrative regions in China from 2000 to 2016, this paper conducts an empirical study of the impact of industrial agglomeration on haze pollution using the spatial Dubin model (SDM), spatial lag model (SLM), and spatial error model (SEM). The findings are as follows: (1) Industrial agglomeration can effectively reduce the degree of haze pollution. (2) Haze pollution has an inverted U-shaped relationship with economic development and population agglomeration. (3) The secondary industry has a positive correlation with haze pollution, while the tertiary industry can reduce haze pollution but not in an obvious manner. (4) The level of innovation and urbanization can help to reduce haze pollution, and the level of economic opening up and carbon dioxide emissions can exacerbate haze pollution. (5) Due to the insufficient commercialization of scientific and technological achievements, investment in science and technology is not obviously effective in preventing and controlling haze pollution. The relationship between environmental regulation and haze pollution is still unclear due to regional differences and the varied effectiveness of law enforcement. The study suggests that the government should guide industrial agglomeration in a reasonable manner, improve joint prevention and control across regions, and strengthen environmental regulation to prevent and control haze pollution.
\end{abstract}

Keywords Industrial agglomeration $\cdot$ Haze pollution $\cdot$ Spatial spillover $\cdot$ Spatial econometrics

\section{Introduction}

Since the initiation of the reform and opening up in 1978, China has been developing at a high speed, and in 2010, it became the world's second largest economy. However, in the process of economic development, China has attached too much importance to economic benefits and ignored negative impacts on the environment. On the one hand, the extensive development model of traditional industries, which is unbalanced and inadequate, has consumed a large amount of fossil energy and the emissions from this model have accelerated air pollution. On the other hand, the unsound energy structure and energy waste may lead to environmental pollution. Haze is

Electronic supplementary material The online version of this article (https://doi.org/10.1007/s11869-020-00884-w) contains supplementary material, which is available to authorized users.

Tao Ma

tiangongmt@126.com

Tianjin University of Finance and Economics, Tianjin, China

2 School of Economics and Management, Tiangong University, Tianjin 300387, China mobile, showing a strong spatial spillover effect. Clarifying the main factors that influence haze transmission across regions holds great significance for controlling haze in a collaborative manner and for promoting coordinated economic and environmental development.

From the new economic geography perspective, if the environment is regarded as a factor of production, industrial agglomeration can achieve a centralized consumption of the environment and improve the utilization efficiency of environmental factors, that is, give full play to the positive externalities and scale effects of the environment, and it can improve the competitiveness and innovation of the enterprises in industrial clusters. However, there is a threshold for industrial agglomeration. When the threshold is exceeded, the negative externalities of industrial agglomeration will exceed the positive externalities, which will reduce the efficiency of resource utilization and exacerbate haze pollution (Wang and Wang 2019; Guo et al. 2020). Therefore, an exploration of the internal mechanism of the impact of industrial agglomeration on haze pollution holds practical significance for promoting "green" economic development and accelerating haze control.

Incorporating industrial agglomeration and haze pollution into a unified analytical framework, and using spatial Dubin 
model (SDM), spatial lag model (SLM), and spatial error model (SEM), this paper empirically analyzes the impact of industrial agglomeration on haze pollution based on statistical data on 30 provinces in China from 2000 to 2016, it investigates the relationship between other control variables and haze pollution, and it proposes countermeasures and suggestions.

\section{Literature review}

Scholars have mainly focused on the influences of industrial agglomeration on air pollution, and some now tend to focus on the influences on haze pollution. Some researchers find that industrial agglomeration exacerbates air pollution. Virkanen (1998) investigates the impact of urbanization on metal deposition in southern Finland and finds that industrial agglomeration is the main cause of air pollution and water eutrophication. Zeng and Zhao (2009) verify the "pollution model" using a spatial econometric model of two countries and two departments, and they find that manufacturing agglomeration and environmental regulation can effectively avoid the "pollution haven" effect. Still, other researchers demonstrate that the relationships between environmental pollution and industrial agglomeration are unclear or nonlinear. Wang and Wang (2019) and Guo et al. (2020) discover that industrial agglomeration and green development have a U-shaped relationship. Li et al. (2020) point out that heavily polluting companies can, through emissions, increase residents' expenditure on health, showing a double threshold effect; that is, the two have an N-shaped relationship. Reizer and Juda-Rezler (2016) study the reasons for the high concentration of PM10 in an urban area of Poland and find that under high atmospheric pressure, PM10 mainly comes from spillovers in Europe and that industry is the main source of PM10.

Based on the panel data of 79 developing countries, Ji et al. (2018) study the relationship between household income, the urbanization level, service industry development, and PM2.5 and find that the goal of reducing pollution emissions can be achieved through the scale effect of industrial agglomeration in the mature phase of urbanization. Ma et al. (2016) conduct research on the connection between haze pollution and economic activities, classifying cities in China into four types according to standards of income and haze pollution. Their research finds that pollution in low-income areas is caused by the agglomeration of pollution-intensive industries, which is suggested to be transferred to low-income unpolluted areas.

Based on the data of 126 countries from 1990 to 2016, Dong et al. (2020) find that the urbanization level has an inverted U-shaped relationship with haze pollution. Haze pollution can be reduced through city cluster effects and technological progress. Germani et al. (2014) analyze the relationship between environmental justice and air pollution in Italian provinces and point out that air pollution shows a spatial agglomeration effect and that improvements in environmental planning and R\&D can effectively reduce air pollution. Based on panel data of China's 269 prefecture-level cities, Yuan et al. (2018) infer that the size of a city can affect the density of PM2.5 through paths such as motor use and changes in the green land area; additionally, population density and centrality, commuting distance, and traffic congestion affect haze pollution. Using China's panel data from 2003 to 2016, Qi et al. (2020) find that urbanization can indirectly affect carbon emissions through trade opening and that advanced industrial structure can also reduce carbon emissions.

Alani et al. (2019) infer that haze pollution has the characteristics of cross-regional transmission in Lagos, Nigeria. Fotourehchi (2016) takes 60 developing countries as samples and points out that the changes in $\mathrm{CO} 2$ and PM10 show the same trend, and the advancement of urbanization level would aggravate pollution. Cetin et al. (2018) point out that traffic intensity is the main PM2.5 and PM10 influencing factors in Bursa city. Chuersuwan et al. (2008) study the main sources of PM2.5 and PM10 and find that vehicle exhaust and material combustion are the main sources of haze pollution in the Bangkok Metropolitan Region (BMR). Based on panel data of 249 Chinese cities, Gan et al. (2020), using urbanization as an intermediary variable, study the relationship between economic development level and haze pollution and find that the two show an $\mathrm{N}$-shaped relationship. $\mathrm{Li}$ et al. (2018) infer that there is a significant spatial spillover effect of haze pollution in the Huang-huai region of China, and industrial agg1lomeration and urbanization will exacerbate haze pollution. Upadhyay et al. (2018) study the health benefits of reducing haze emissions in India and find that industry, transportation, and energy are the main sources of haze pollution. Using the GTWR model, Dong et al. (2020) analyze Chinese provincial panel data from 1998 to 2015 and discover that industrial agglomeration exacerbates environmental pollution at both the national and provincial levels but that the impact at the provincial level varies slightly across different provinces; that is, the positive effect in eastern and northern is stronger while that in western is weaker. By comparison, we find that the effect of industrial agglomeration on haze pollution in studies conducted outside of China is generally positive, while Chinese studies on the relationship between the two have not yet reached a unified conclusion.

The above literature review shows that the relationship between industrial agglomeration and air pollution has drawn much academic attention and that some progress has been made; however, little attention has been paid to industrial agglomeration and haze pollution. Within the spatial econometric model framework, this paper investigates the impact of industrial agglomeration on haze pollution in 30 provincial administrative regions of China from 2000 to 2016, and based on the relationships between haze pollution and its 
independent variables, it proposes some feasible suggestions and countermeasures. As an innovation with regard to the above-mentioned studies, this paper selects more indicators that affect haze pollution and is the first study to include carbon emissions. The relationships between haze pollution and carbon emissions are explored to offer suggestions on the coordinated control of the greenhouse effect and haze pollution. Moreover, as a further development of the above studies, this paper verifies the nonlinear relationship between economic development, population density, and haze pollution, and it tries to find the best way of balancing economic development, population agglomeration, and haze pollution. From an international perspective, the novelty/originality of this paper refines the existing analytical framework and has implications for developing countries in studying the factors of haze pollution.

\section{Research design}

\section{Empirical model}

Considering the spatial spillover effect of industrial agglomeration and haze pollution (Dong et al. 2019), this paper adopts spatial econometric models to explore the relationship between them. In this regard, spatial econometrics can more accurately estimate the relationship between and the strength of spatial variables. Traditional spatial econometric models mainly include the spatial Dubin model (SDM), spatial lag model (SLM), and spatial error model (SEM). SLM model addresses whether there is a spatial spillover effect on each variable. The SEM investigates the random impact of dependent variables in adjacent areas on the dependent variables in a focal area. The SDM can solve the problem of missing variables and effectively prevent missing variables from being biased. The calculation formulas are as follows:

$Y_{i t}=\rho W Y_{i t}+\beta X_{i t}+\mu_{i}+\lambda_{t}+\varepsilon_{i t}$

where $X_{i t}$ and $Y_{i t}$ are the independent variable and dependent variable, $W Y_{i t}$ is the spatial lag term of the dependent variable $Y_{i t}, \mu_{i}$, and $\lambda_{t}$ refer to the individual and time fixed effects, and $\varepsilon_{i t}$ is the stochastic disturbance team.

$Y_{i t}=\beta X_{i t}+\mu_{i}+\lambda_{t}+\varepsilon_{i t}, \varepsilon_{i t}=\delta W \varepsilon_{i t}+\phi$

where $\varepsilon_{i t}$ is the autocorrelation of spatial error and $\phi$ is the corresponding coefficient.

$Y_{i t}=\rho W Y_{i t}+\beta X_{i t}+\vartheta W X_{i t}+\mu_{i}+\lambda_{t}+\varepsilon_{i t}$

To analyze the impact of industrial agglomeration on haze pollution, this research constructs the SLM, SEM, and SDM as follows:

$$
\begin{aligned}
\text { pm2.5 }= & \beta_{0}+\rho W \text { pm } 2.5+\beta_{1} \text { agg }+\beta_{2} \text { pdgp } \\
& +\beta_{3} \text { sqpgdp }+\beta_{4} \text { ind }+\beta_{5} \text { ind }+\beta_{6} \text { pden } \\
& +\beta_{7} \text { sqpden }+\beta_{8} \text { rd }+\beta_{9} \text { open }+\beta_{10} \cos 2 \\
& +\beta_{11} \text { inno }+\beta_{12} \text { urban }+\beta_{13} \text { er }+\mu+\lambda+\varepsilon \\
\text { pm2.5 }= & \beta_{0}+\beta_{1} \text { agg }+\beta_{2} \text { pgdp }+\beta_{3} \text { sqpgdp }+\beta_{4} \text { ind } \\
& +\beta_{5} \text { ind }+\beta_{6} \text { pden }+\beta_{7} \text { pden }+\beta_{8} \text { rd } \\
& +\beta_{9} \text { open }+\beta_{10} \cos 2+\beta_{11} \text { inno }+\beta_{12} \text { urban } \\
& +\beta_{13} \text { er }+\mu+\lambda+\varepsilon, \varepsilon \\
= & \delta W \varepsilon+\phi
\end{aligned}
$$

$$
\begin{aligned}
\text { pm2.5 }= & \beta_{0}+\rho W \text { pm } 2.5+\beta_{1} \text { agg }+\beta_{2} \text { pgdp } \\
& +\beta_{3} \text { sqpgdp }+\beta_{4} \text { 2ind }+\beta_{5} \text { ind }+\beta_{6} \text { pden } \\
& +\beta_{7} \text { sqpden }+\beta_{8} \text { rd }+\beta_{9} \text { open }+\beta_{10} \cos 2 \\
& +\beta_{11} \text { inno }+\beta_{12} \text { urban }+\beta_{13} \text { er }+\theta_{1} \text { agg } \\
& +\theta_{2} \text { pgdp }+\theta_{3} \text { sqpgdp }+\theta_{4} \text { ind }+\theta_{5} \text { ind } \\
& +\theta_{6} \text { pden }+\theta_{7} \text { sqpden }+\theta_{8} \text { rd }+\theta_{9} \text { open } \\
& +\theta_{10} \cos 2+\theta_{11} \text { inno }+\theta_{12} \text { urban }+\theta_{13} \text { er }+\mu \\
& +\sigma+\varepsilon
\end{aligned}
$$

In these models, "pm2.5" represents haze pollution concentration, "agg" denotes the location entropy of industrial agglomeration, "pgdp" means per capita GDP, "sqpgdp" represents the quadratic term of per capita GDP, " 2 ind" is the structure of the secondary industrial, " 3 ind" refers to the structure of the tertiary industry, "pden" is population density, "sqpden" denotes the quadratic term of population density, "rd" represents the intensity of R\&D, "open" reflects the degree of opening up, "co2" is the carbon dioxide emissions, "inno" refers to the number of patent applications, "urban" denotes the level of urbanization, and "er" represents environmental regulations.

\section{Variable selection}

Explained variable: haze pollution (PM2.5) This paper obtains PM2.5 data from the remote sensing map published by the Socioeconomic Data and Application Center at Columbia University. Then, using ArcGIS software, it extracts the annual mean data on PM2.5 in 30 provincial-level administrative regions of China. 
Core explanatory variable: industrial agglomeration (agg) This paper chooses location entropy as the indicator to measure industrial agglomeration.

Control variables Ehrlich and Holdren (1971) proposed the IPAT model to study the impact of socioeconomic factors, namely population, prosperity, and technology, on environmental pollution. On the basis of the above factors, this paper adds variables such as the industrial structure, carbon dioxide emissions, the urbanization level, and environmental regulations to the model to perform a more accurate analysis of the relationships between haze pollution and industrial agglomeration. The additional variables are as follows:

Economic development (pgdp) In general, regions with a high level of economic development produce more products and consume more energy than other regions do, thus exacerbating haze pollution. This article uses the actual per capita GDP data that have been converted into 2000 constant prices to measure the economic development level. Meanwhile, to verify the environmental Kuznets curve (EKC) of environmental pollution and economic development, the quadratic term of per capita GDP (sqpgdp) is included.

Industrial structure The rapid development of industrialization stimulates the large demand for petrochemical energy and leads to serious haze pollution. Continuous optimization of industrial structure, in which the tertiary industry mainly depends on technological progress and innovation, can effectively alleviate haze pollution. Therefore, this paper chooses the ratio of the output value of the secondary industry to GDP (2ind) and the ratio of the tertiary industry to GDP (3ind) to measure China's industrial structure.

Population agglomeration Moderate population agglomeration helps to reduce haze pollution, while excessive gathering exacerbates it. In this paper, population density (pden) is selected as an indicator to measure population agglomeration, and the quadratic term of population density (sqpden) is also included.

Technology investment Previous studies show contradictory results regarding the relationship between technology investment and haze pollution. To clarify the relationship between the two, this paper selects the ratio of $R \& D$ investment to GDP as an alternative variable of technology investment.

Opening up Opening up to the outside world helps to accelerate a country's process of industrial agglomeration, and thus, it affects haze pollution. Therefore, this paper chooses the ratio of foreign direct investment (FDI) (converted into $\mathrm{RMB}$ at the annual average exchange rate price in the current year) to GDP as a means of measuring the level of opening up.
Carbon dioxide emissions (CO2) Haze pollution is closely related to carbon dioxide emissions. Thus, this paper selects $\mathrm{CO} 2$ emissions to measure their relationship with haze pollution.

Innovation level (inno) This paper takes the total number of domestic patent applications in 30 provincial administrative regions as the yardstick for measuring the level of innovation.

Urbanization (urban) In the initial stage of urbanization, the massive use of energy leads to heavy haze pollution, but in the mature stage, energy consumption is effective in restraining haze pollution by improving energy efficiency and promoting economic agglomeration. Therefore, this article selects the urbanization rate to measure the level of urbanization.

Environmental regulation (er) The stricter the environmental regulations are, the more closely companies pay attention to pollution control and emission reduction. This can effectively promote the upgrading of enterprises and the innovation of environmental protection technology. In this paper, the level of environmental regulation is measured by the ratio of total sewage charges to GDP.

\section{Data source}

The haze pollution data in this paper come from the Socioeconomic Data and Application Center at Columbia University. All the data for the core explanatory variables and control variables come from the China Statistical Yearbook, the statistical yearbooks of provinces and cities, the China Energy Yearbook, and China City Yearbook. Missing data are supplemented by linear interpolation. All these data cover 30 provincial administrative regions in China from 2000 to 2016. The basic descriptive statistical information of the variables is shown in Table S1.

\section{Analysis of the empirical results}

This paper uses spatial econometric models to analyze the correlation between industrial agglomeration and haze pollution. In view of the possibility that different spatial correlation models produce different spatial effects, this paper uses the adjacency weight matrix, inverse distance weight matrix, and economic weight matrix to test the robustness of the regression results, and it carries out SLM, SEM, and SDM regression analysis under the three respective weight matrices, and introduces OLS model estimation. First, the Hausman test result is 0.0148 . At the significance level of 0.05 , we reject the null hypothesis of random effects, choose a fixed-effects model, and set time fixed, space fixed, and time-space fixed effects. The OLS and spatial-time fixed regression results under adjacency weight matrix are shown in Table S2, the OLS 
and spatial-time fixed regression results under inverse distance weight matrix are shown in Table S3, the OLS and spatial-time fixed regression results under economic weight matrix are shown in Table S4, the results of the spatial fixed and time fixed regression results under adjacency weight matrix are shown in Table S5, the results of the spatial fixed and time fixed regression results under inverse distance weight matrix are shown in Table S6, and the results of the spatial fixed and time fixed regression results under economic weight matrix are shown in Table S7.

According to the empirical results in Table S2 to S7, the direction and prominence of each variable coefficient do not change significantly under the three spatial weight matrices, indicating that the model setting is reasonable and that the credibility of the estimated results is high.

\section{The impact of the core explanatory variables on haze pollution}

The industrial agglomeration coefficient has a negative sign under the three kinds of spatial weight matrices and passes the significance test at the $1 \%$ level, showing that industrial agglomeration can significantly reduce haze pollution and has positive externalities. Two reasons explain the result. First, industrial agglomeration can more effectively take the advantage of the division of labor, promote the forward and backward linkages between enterprises, and reduce exhaust in road transportation during the supply of raw materials, the production of intermediate products, and the sales of final products. Industrial agglomeration can also improve the efficiency of allocation and utilization of energy elements among enterprises and thus play a significant role in reducing haze pollution. Second, the forward and backward linkages of enterprises can reduce transaction costs and increase investment in clean energy and technology. Industrial agglomeration can also promote competition between enterprises, stimulate the innovation vitality of enterprises, help enterprises to cooperate in technology development and share technological achievements despite the competition among them, and realize the goal of energy saving and emission reduction on the basis of shared development.

\section{The impact of the control variables on haze pollution}

Economic development GDP per capita is significant and the coefficient is positive under three weight matrices, indicating that economic development is positively correlated with environmental pollution. This is related to China's early extensive development, which has led to heavy energy consumption and environmental pollution. The positive coefficient of GDP per capita and the negative coefficient of the quadratic term of GDP per capita indicate that haze pollution and the level of economic development do not have a simple linear relationship but an inverted U-shaped relationship, verifying the environmental Kuznets curve (EKC) of environmental pollution and economic development.

Industrial structure The structure of secondary industry and the structure of tertiary industry are both significant under the three weight matrices. The positive coefficient of the structure of the secondary industry indicates that the secondary industry is positively related to haze pollution. The reason is that China has paid too much attention to economic benefits in the development process and has not paid enough attention to environmental pollution. The coefficient of the structure of the tertiary industry is negative, indicating that the development of the tertiary industry can suppress haze pollution because the tertiary industry is mostly consisting of service sectors. In addition, the absolute value of the coefficient of the structure of the tertiary industry structure coefficient is much smaller than that of the secondary industry, showing that although China's industrial structure is continuously optimized and the output value of the tertiary industry has increased significantly, its emission reduction effect has not improved significantly and that the process of industrial structure upgrading still needs to be further promoted.

Population agglomeration Population density and its quadratic terms are significant at the $1 \%$ level in the three weight matrices. The positive coefficient of population density indicates that population agglomeration may intensify haze pollution because population concentration will lead to increased consumption and travel, consume more energy, and produce more automobile exhaust. The negative coefficient of the quadratic term of population density further verifies the inverted U-shaped relationship between population density and haze pollution, indicating that the scale effect of population agglomeration has already appeared.

Technology investment The coefficient of technology investment is positive under the three weight matrices, indicating that technology investment has not produced satisfactory effects on emission reduction and haze pollution is still increasing. The reasons may be the process of transforming, the achievements of scientific research into real-world is inefficient and delayed, and that the application of energy-saving and emission-reducing technologies is not sufficient. On the other hand, the application of innovation achievements may lead to the rebound effect of energy, and the emission reduction effects brought by technological progress may be offset by a new round of energy consumption and pollutant emissions brought by a deepening of capital and an increase in output, thus 
resulting in a nonsignificant emission reduction effect of science and technology investment.

Opening up The regression coefficient of the level opening up is significantly positive under the three weight matrices, indicating that FDI is positively correlated with haze pollution. One possible explanation is that since the initiation of the reform and opening up, China has constantly attracted foreign capital due to its comparative advantages in labor costs and natural resources. However, foreign-invested enterprises are generally labor-intensive, heavily polluting, and high-energyconsuming enterprises, and their economic activities have led to increased haze pollution. The inflow of FDI drives more labor and resources, increasing the scale of resource consumption; this structural effect and scale effect lead to the promotion of economic development while also increasing haze pollution. FDI promotes the local economic scale by increasing the capital stock of the host country, leading to an increase in pollutant emissions and deepening the pollution level of the local industrial structure.

Carbon dioxide emissions The $\mathrm{CO} 2$ emission coefficient is significant at the $1 \%$ level in all three weight matrices, indicating a highly positive correlation between the two. The reason for this result is that the combustion of fossil energy can produce both $\mathrm{CO} 2$ and particulate matter, which gradually develops into haze. Since carbon dioxide and haze have the same homology, the dual strategy of simultaneously reducing carbon emissions and reducing haze pollution should be considered when formulating environmental policies.

Innovation level The negative regression coefficient of the innovation level indicates that improving innovation level can effectively reduce haze pollution. The reason is that innovation can promote the development of high-tech industry, optimize and upgrade the economic structure, change growth drivers, and ultimately, reduce haze pollution. Innovation can also improve the efficiency of resource allocation and total factor productivity by optimizing the industry structure and the allocation of resources, ultimately mitigating the loss of energy efficiency caused by irrational resource allocation and thus reducing the level of haze pollution. Innovation level can contribute to technological progress in mitigating urban haze through the technology effect. Cities with a higher level of innovation have intelligent pollution monitoring platforms that, through real-time monitoring, improve the city's efficiency in the mid-range process of the monitoring of corporate emissions and the ability of companies to monitor their own emissions and access to pollution information to mitigate haze causing emissions.

Urbanization level The negative coefficient of the urbanization rate indicates that improving urbanization rate is helpful in reducing haze pollution. On the one hand, urbanization can promote the formation of economic agglomeration; attract capital, labor, and technological innovation; improve the efficiency of resource utilization; and reduce the energy consumption per unit of GDP. On the other hand, in this paper, the regression coefficient of the urbanization rate is small, which shows that its impact on reducing haze pollution is not yet obvious.

Environmental regulation The coefficient of environmental regulation on haze pollution is not significant, and therefore, the relationship between them cannot be judged. The reason why the regression coefficient is large but nonsignificant may be that the effect of environmental regulations on haze pollution is significant but implementation varies in different places. Meanwhile, Li et al. (2019) prove that environmental regulation has a spatial spillover effect and lag effect on haze pollution, but the effects vary within regions. This finding further shows that a single environmental regulation may produce different effects in different regions, leading to nonsignificant regression results.

\section{Conclusions and policy implications}

Based on the adjacency weight matrix, inverse distance weight matrix, and economic weight matrix, this paper empirically studies the impact of industrial agglomeration on haze pollution using the spatial Dubin model (SDM), spatial lag model (SLM), and spatial error model (SEM). The findings are as follows: (1) Although industrial agglomeration can effectively reduce haze pollution, excessive industrial agglomeration may lead to congestion, resources waste, and aggravated haze pollution. (2) This article verifies that there is an environmental Kuznets curve (EKC) between China's environmental pollution and economic development. That is, the two have an inverted U-shaped relationship, and the same relationship exists between population agglomeration and haze pollution. (3) In terms of the industrial structure, the secondary industry has a positive correlation with haze pollution, while the tertiary industry is effective in reducing haze pollution, but has a nonsignificant reducing emission. (4) Opening up and carbon dioxide emissions aggravate haze pollution. Technological investment, due to its low transformation rate, has not been proven effective in haze control thus far. A higher level of innovation and a higher urbanization rate help to reduce haze pollution. (5) Environmental regulations are not obviously related to haze pollution but are effective in reducing emissions.

Based on the above findings, this research proposes the following policy implications: 
The government should guide industrial agglomeration in a reasonable way and coordinate economic development and environmental protection

Regional development planning should take local advantages into account. From a regional perspective, the eastern provinces are competitive in information, technology, and infrastructure, while the western provinces have advantages in labor and natural resources. Specifically, eastern provinces should be committed to developing a headquarters economy represented by financial services and $R \& D$ consulting services, as to focusing on high-end producer services and consumer services. Western provinces should be committed to promoting the cluster development of advanced manufacturing industries such as new energy and new materials to realize the coordinated development of cultivating new kinetic energy and upgrading traditional kinetic energy, thereby promoting improvement in economic quality and reducing in haze pollution. Therefore, it is necessary to integrate the advantages of different regions to accelerate the process of industrial structure upgrading and industry transfer and to rationalize the industrial layout. Efforts should be made to encourage the development of the tertiary industry and high-tech industries to increase investment in R\&D and human capital, encourage technological innovation, and to accelerate the transformation of scientific research achievements and their application in the market.

The government should strengthen cooperation between regions and improve the mechanism of joint prevention and control of haze

Haze has a significant spatial spillover effect. Therefore, enterprises should strengthen cooperation and dialogue with forward and backward enterprises, work together in the development of cleaner production technologies, and jointly design the implementation of emission reduction plans. On the one hand, the government should create a market mechanism that encourages enterprises to make technological innovations, and establish a long-term mechanism to encourage enterprises to strengthen the research and development of new energy and new technologies. On the other hand, it needs to enhance cooperation with neighboring regions and accelerate the establishment of regional environmental monitoring platforms, information sharing platforms, joint law enforcement platforms, and unified planning platforms to avoid fragmented control of haze. Moreover, considering that carbon dioxide emissions and haze come from the same source, we may try measures that target both carbon emissions and haze pollution.

The government should strengthen environmental regulations and provide institutional support for pollution prevention

Local governments should formulate stricter environmental regulations and policies and strengthen law enforcement. Compared with the possible "beggar thy neighbor" in haze pollution, environmental regulation is prone to "free-riding" due to its spatial spillover effect. Therefore, local governments should formulate stricter environmental regulations and policies, implement them effectively, and coordinate with neighboring regions to realize coordinated economy and environment development. For enterprises with weak pollution reduction technologies and poor R\&D capabilities, environmental administrative control should be strengthened to improve their pollution reduction capabilities, but for enterprises with strong R\&D capabilities, excessive administrative intervention in their business activities should be avoided as far as possible, and more market-oriented regulatory tools should be adopted to encourage enterprises to engage in green technology innovation.

Acknowledgments This article is supported by the National research programme of statistical science: Research on the Indicators and Appraisal of Environmental Risks in Industrial Distribution under the Strategy of Beijing-Tianjin-Hebei Integration (a privileged program) (approved serial number: 2016435).

\section{Compliance with ethical standards}

Conflict of interest The authors declare that they have no conflict of interest.

Open Access This article is licensed under a Creative Commons Attribution 4.0 International License, which permits use, sharing, adaptation, distribution and reproduction in any medium or format, as long as you give appropriate credit to the original author(s) and the source, provide a link to the Creative Commons licence, and indicate if changes were made. The images or other third party material in this article are included in the article's Creative Commons licence, unless indicated otherwise in a credit line to the material. If material is not included in the article's Creative Commons licence and your intended use is not permitted by statutory regulation or exceeds the permitted use, you will need to obtain permission directly from the copyright holder. To view a copy of this licence, visit http://creativecommons.org/licenses/by/4.0/.

\section{References}

Alani RA, Ayejuyo OO, Akinrinade OE, Badmus GO, Alo BI (2019) The level PM2.5 and the elemental compositions of some potential receptor locations in Lagos, Nigeria. Air Qual Atmos Health 12:12511258. https://doi.org/10.1007/s11869-019-00743-3

Cetin M, Onac AK, Sevik H, Sen B (2018) Temporal and regional change of some air pollution parameters in Bursa. Air Qual Atmos Health 12:311-316. https://doi.org/10.1007/s11869-018-00657-6

Chuersuwan N, Nimrat S, Lekphet S, Kerdkumrai T (2008) Levels and major sources of PM2.5 and PM10 in Bangkok Metropolitan Region. Environ Int 34:671-677. https://doi.org/10.1016/j.envint. 2007.12.018

Dong F, Wang Y, Zheng L, Li J, Xie S (2019) Can industrial agglomeration promote pollution agglomeration? Evidence from China. J Clean Prod 246:118960. https://doi.org/10.1016/j.jclepro.2019. 118960

Dong Q, Lin Y, Huang J, Chen Z (2020) Has urbanization accelerated PM2. 5 emissions? An empirical analysis with cross-country data. China Economic Review 59:101381. https://doi.org/10.1016/j. chieco.2019.101381 
Ehrlich PR, Holdren JP (1971) Impact of population growth. Science 171(3977):1212-1217. https://doi.org/10.1126/science.171.3977. 1212

Fotourehchi Z (2016) Health effects of air pollution: an empirical analysis for developing countries. Atmos Pollut Res 7:201-206. https://doi. org/10.1016/j.apr.2015.08.011

Gan T, Liang W, Yang H, Liao X (2020) The effect of economic development on haze pollution (PM 2.5 ) based on a spatial perspective: urbanization as a mediating variable. J Clean Prod 266:121880. https://doi.org/10.1016/j.jclepro.2020.121880

Germani AR, Morone P, Testa G (2014) Environmental justice and air pollution: a case study on Italian provinces. Ecol Econ 106:69-82. https://doi.org/10.1016/j.ecolecon.2014.07.010

Guo Y, Tong L, Mei L (2020) The effect of industrial agglomeration on green development efficiency in Northeast China since the revitalization. J Clean Prod 258:120584. https://doi.org/10.1016/j.jclepro. 2020.120584

Ji X, Yao Y, Long X (2018) What causes PM2. 5 pollution? Crosseconomy empirical analysis from socioeconomic perspective. Energy Policy 119:458-472. https://doi.org/10.1016/j.enpol.2018. 04.040

Li M, Li C, Zhang M (2018) Exploring the spatial spillover effects of industrialization and urbanization factors on pollutants emissions in China's Huang-Huai-Hai region. J Clean Prod 195:154-162. https:// doi.org/10.1016/j.jclepro.2018.05.186

Li L, Liu X, Ge J, Chu X, Wang J (2019) Regional differences in spatial spillover and hysteresis effects: a theoretical and empirical study of environmental regulations on haze pollution in China. J Clean Prod 230:1096-1110. https://doi.org/10.1007/s11869-014-0300-9

Li H, Lu J, Li B (2020) Does pollution-intensive industrial agglomeration increase residents' health expenditure? Sustain Cities Soc 56: 102092. https://doi.org/10.1016/j.scs.2020.102092
Ma Y, Ji Q, Fan Y (2016) Spatial linkage analysis of the impact of regional economic activities on PM2. 5 pollution in China. J Clean Prod 139:1157-1167. https://doi.org/10.1016/j.jclepro.2016.08.152

Qi X, Han Y, Kou P (2020) Population urbanization, trade openness and carbon emissions: an empirical analysis based on China. Air Qual Atmos Health 13:519-528. https://doi.org/10.1007/s11869-02000808-8

Reizer M, Juda-Rezler K (2016) Explaining the high PM(10) concentrations observed in Polish urban areas. Air Qual Atmos Health 9:517531. https://doi.org/10.1007/s11869-015-0358-z

Upadhyay A, Dey S, Chowdhury S, Goyal P (2018) Expected health benefits from mitigation of emissions from major anthropogenic $\operatorname{PM}(2.5)$ sources in India: Statistics at state level. Environ Pollut 242:1817-1826. https://doi.org/10.1016/j.envpol.2018.07.085

Virkanen J (1998) Effect of urbanization on metal deposition in the bay of Töölönlahti, Southern Finland. Mar Pollut Bull 36:729-738. https:// doi.org/10.1016/S0025-326X(98)00053-8

Wang Y, Wang J (2019) Does industrial agglomeration facilitate environmental performance: new evidence from urban China? J Environ Manage 248:109244. https://doi.org/10.1016/j.jenvman.2019.07. 015

Yuan M, Huang Y, Shen H, Li T (2018) Effects of urban form on haze pollution in China: spatial regression analysis based on PM2.5 remote sensing data. Appl Geogr 98:215-223. https://doi.org/10. 1016/j.apgeog.2018.07.018

Zeng DZ, Zhao L (2009) Pollution havens and industrial agglomeration. J Environ Manage 58:141-153. https://doi.org/10.1016/j.jeem.2008. 09.003

Publisher's note Springer Nature remains neutral with regard to jurisdictional claims in published maps and institutional affiliations. 